\title{
Comparison of Two Renal Cell Lines (NRK-52E and LLC-PK1) as Late Stage Apoptosis Models
}

\author{
Alexandra H. Heussner, Daniel R. Dietrich ${ }^{*}$ \\ Human and Environmental Toxicology, University of Konstanz, Konstanz, Germany \\ Email: *daniel.dietrich@uni-konstanz.de
}

Received March 12, 2013; revised April 12, 2013; accepted April 22, 2013

Copyright (C) 2013 Alexandra H. Heussner, Daniel R. Dietrich. This is an open access article distributed under the Creative Commons Attribution License, which permits unrestricted use, distribution, and reproduction in any medium, provided the original work is properly cited.

\begin{abstract}
Renal cell lines are frequently used models in toxicology. The aim of the experiments described here was to investigate the suitability of two of those renal cell lines, namely NRK-52E and LLC-PK1, as models for mid to late stage apoptosis under standard cell culture conditions; the latter means that testing was performed in the presence of serum in the culture media. Seven known inducers of apoptosis already positively tested by other investigators were chosen as test substances using chromatin condensation (Hoechst staining) as endpoint. These substances were cadmium chloride $\left(\mathrm{CdCl}_{2}\right)$, dithiothreitol (DTT), sodium chloride $(\mathrm{NaCl})$, mercuric chloride $\left(\mathrm{HgCl}_{2}\right)$, tributyltin oxide (TBT-O), tributyltin chloride (TBT-Cl) and staurosporine. From these, only TBT-O, TBT-Cl and staurosporine induced morphological features typical of apoptosis in LLC-PK1 cells. Morphologically discerned apoptosis was confirmed by DNA fragmentation (DNA laddering assay) analysis. LLC-PK1 cells, but not NRK-52E cells, were shown to be suitable models of mid to late stage apoptosis under the conditions employed. TBT-O, TBT-Cl and staurosporine were shown to be suitable positive controls for apoptosis in renal cells in vitro.
\end{abstract}

Keywords: Renal Cell Lines; Hoechst 33342; DNA Laddering

\section{Introduction}

Continuous renal cell lines are frequently used cell models in toxicology due to their technical and economic advantages over primary cells or in vivo solutions. Especially NRK-52E (rat), LLC-PK1 (pig), MDCK (dog), VERO (monkey), BHK (hamster) and OK (opossum) are used extensively for investigation of mechanisms and signal transduction pathways in toxicology.

The aim of the project presented here was to investigate the suitability of two of these renal cell lines, namely NRK-52E and LLC-PK1, with respect to their sensitivity to various known apoptosis inducers using mid to late stage apoptosis, i.e. chromatin condensation and DNA fragmentation, as endpoints.

Nuclear chromatin condensation and chromosomal DNA fragmentation are well-described key features in apoptosis and are strikingly similar in different cell types [1]. The chromatin condensation is microscopically visible as dense chromatin aggregates typically near to the nuclear membrane, e.g. after staining with certain dyes such as the blue-fluorescent Hoechst 33,342 dye staining

${ }^{*}$ Corresponding author. condensed chromatin of apoptotic cells more brightly than the chromatin of normal cells. Condensed chromatin with a distinct fragment size, roughly $180-200$ base pairs and multiples thereof, is the result of a specific DNA fragmentation via cleavage by endogenous endonucleases. The latter DNA fragments can be used as a marker for apoptosis, e.g. via the DNA laddering assay [1]. In contrast, necrosis is typically characterized by random DNA fragmentation resulting in a DNA smear rather than a distinct ladder in DNA agarose gel electrophoresis.

The set of test substances, reportedly used as positive controls for apoptosis induction in in vitro cell systems, included cadmium chloride $\left(\mathrm{CdCl}_{2}\right)$, dithiothreitol (DTT), sodium chloride $(\mathrm{NaCl})$, mercuric chloride $\left(\mathrm{HgCl}_{2}\right)$, tributyltin oxide (TBT-O), tributyltin chloride (TBT-Cl) and staurosporine [2-14].

\section{Materials and Methods}

\subsection{Materials}

Unless stated otherwise, materials and chemicals were purchased as follows: PAA Laboratories $\mathrm{GmbH}$, Cölbe, 
Germany (cell culture chemicals), Greiner Bio-One $\mathrm{GmbH}$, Frickenhausen, Germany (cell culture plastics), and Sigma-Aldrich $\mathrm{GmbH}$, Seelze, Germany (all other chemicals).

\subsection{Test Substances}

Cadmium chloride $\left(\mathrm{CdCl}_{2}\right)$, dithiothreitol (DTT), sodium chloride $(\mathrm{NaCl})$ and mercury chloride $\left(\mathrm{HgCl}_{2}\right)$ stock solutions were prepared in deionized water. Tributyltin oxide (TBT-O) and tributyltin chloride (TBT-Cl) were dissolved in absolute ethanol and staurosporine stock solution was prepared in dimethylsulfoxide (DMSO) (Merck, Darmstadt, Germany). All stock solutions were sterilized by filtration $(0.2 \mu \mathrm{m})$, diluted in the corresponding solvent and added to cell culture medium using a dilution factor of 40 . Final solvent concentrations were $0.5 \%(\mathrm{v} / \mathrm{v})$ for all solvents employed. The latter solvent concentrations were previously shown to have no significant adverse effect on the cell types used (data not shown).

\subsection{Cell Culture and Treatments}

LLC-PK1 and NRK-52E cells were obtained from the European Collection of Cell Cultures, Salisbury, UK (ECACC \# 86121112) and from the DSMZ, Braunschweig, Germany (DSMZ \#ACC 199), respectively. Both cell lines were cultured in DMEM supplemented with $10 \%$ FBS and antibiotics (with a final concentration of $100,000 \mathrm{U} / \mathrm{L}$ penicillin and $100 \mathrm{mg} / \mathrm{L}$ streptomycin) under standard conditions $\left(37^{\circ} \mathrm{C}, 5 \% \mathrm{CO}_{2}\right)$ and subcultured twice per week with a dilution ratio of $1: 10$. Passages 2 - 18 were used for experiments. Cells were seeded at a density of $1 \times 10^{4}$ cells cm $\mathrm{cm}^{-2}$ in $21 \mathrm{~cm}^{2}$ tissue culture Petri dishes for Hoechst staining and in $175 \mathrm{~cm}^{2}$ flasks for DNA laddering. Incubations (2 to 48 hours) with the test compounds (Table 1) commenced 24 hours after seeding.

\subsection{Hoechst Staining}

Following compound exposure cell cultures were washed with modified PBS (136.9 mM NaCl, $2.7 \mathrm{mM} \mathrm{KCl}, 8.1$ $\mathrm{mM} \mathrm{Na}_{2} \mathrm{HPO}_{4}, 1.5 \mathrm{mM} \mathrm{KH} \mathrm{PO}_{4}, \mathrm{pH} 7,4,300$ mosM) and then fixed with ice-cold absolute methanol for 10 minutes. After 7 minutes incubation with Hoechst 33,342 dye solution ( $1 \mu \mathrm{M}$ in PBS) at room temperature, samples were washed again with PBS and a cover-slip was mounted with anti-fading mounting medium (cat\# S3023, Dako, Hamburg, Germany). After storage at $4^{\circ} \mathrm{C}$ over-night, chromatin condensation was evaluated visually using a microscope equipped with a broad range UV light excitation filter and then photographed for documentation.

\subsection{DNA extraction and DNA-Laddering}

The DNA laddering assays were performed according to a previously published method [15] with slight modifications. Briefly, after compound exposure cellular DNA was isolated via phenolic extraction. The purity and amount of DNA isolated was determined spectrophotometrically. DNA samples were separated on a $1.8 \%$ agarose gel and visualized after ethidium bromide staining on a UV screen and photographs were taken.

\section{Results}

\subsection{Hoechst Staining}

NRK-52E and LLC-PK1 cells were exposed to seven different compounds (Table 1). The concentrations and exposure durations were chosen based on literature data [2-14]. All exposures were performed and analyzed using standard conditions, i.e. in medium supplemented with $10 \%$ FBS. Representative microscopic pictures are shown in Figure 1. Interestingly, in LLC-PK1 cells four out of seven compounds, and in NRK-52E all compounds failed to elicit measurable apoptosis (Table 1). In order to elucidate whether the FBS content could be re-

Table 1. Hoechst staining results in LLC-PK1 and NRK-52E cells.

\begin{tabular}{|c|c|c|c|c|c|c|}
\hline \multirow{2}{*}{ Substance } & \multirow{2}{*}{$\begin{array}{c}\text { Final } \\
\text { concentrations }\end{array}$} & \multirow{2}{*}{$\begin{array}{l}\text { Exposure } \\
\text { time }(\mathrm{h})\end{array}$} & \multicolumn{2}{|c|}{ LLC-PK1 } & \multicolumn{2}{|c|}{ NRK-52E } \\
\hline & & & $10 \% \mathrm{FBS}$ & $0 \%$ FBS & $10 \% \mathrm{FBS}$ & $0 \% \mathrm{FBS}$ \\
\hline $\mathrm{CdCl}_{2}$ & $5-40 \mu \mathrm{M}$ & $4-48$ & no effect & $\begin{array}{l}20 \mu \mathrm{M}(\geq 24 \mathrm{~h}) \\
40 \mu \mathrm{M}(\geq 14 \mathrm{~h})\end{array}$ & no effect & no effect \\
\hline DTT & $1-50 \mathrm{mM}$ & $2-48$ & no effect & no effect & no effect & no effect \\
\hline $\mathrm{HgCl}_{2}$ & $1-40 \mu \mathrm{M}$ & $2-48$ & no effect & $40 \mu \mathrm{M}(48 \mathrm{~h})$ & no effect & no effect \\
\hline $\mathrm{NaCl}$ & $500-900$ mosM & $4-48$ & no effect & no effect & no effect & no effect \\
\hline Staurosporine & $0.1-5 \mu \mathrm{M}$ & $2-48$ & $\geq 0.1 \mu \mathrm{M}(\geq 4 \mathrm{~h})$ & n.d. & no effect & n.d. \\
\hline TBT-O & $0.05-2 \mu \mathrm{M}$ & $2-8$ & $\geq 0.5 \mu \mathrm{M}(\geq 2 \mathrm{~h})$ & n.d. & no effect & n.d. \\
\hline TBT-Cl & $0.1-10 \mu \mathrm{M}$ & $2-8$ & $\geq 1 \mu \mathrm{M}(\geq 4 \mathrm{~h})$ & n.d. & no effect & n.d. \\
\hline
\end{tabular}

n.d., not determined. 

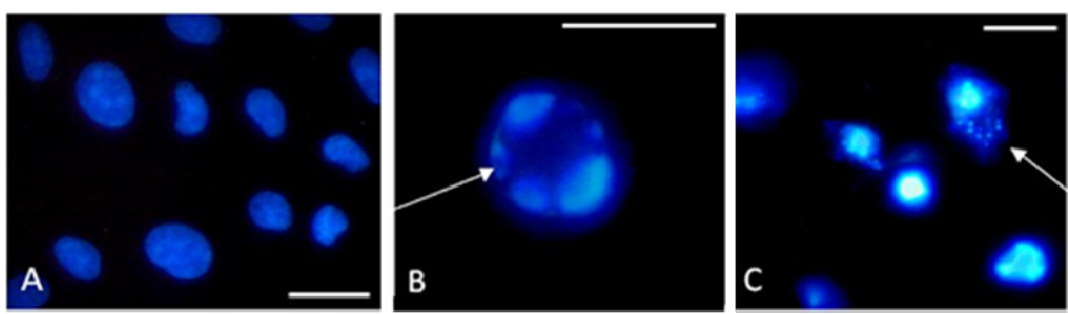

Figure 1. Representative pictures from Hoechst staining experiments with LLC-PK1. (A), untreated; (B), $1 \mu M$ staurosporine (12 h); (C), 5 нM TBT-Cl (4 h); bar = $20 \mu \mathrm{m}$.

sponsible for these results, the assays were repeated for the non-inducers without FBS addition. In LLC-PK1 cells, two compounds, i.e. cadmium chloride $\left(\mathrm{CdCl}_{2}\right)$ and mercuric chloride $\left(\mathrm{HgCl}_{2}\right)$, showed distinct signs of apoptosis, although at rather high concentrations and long incubation times (Table 1). The other two known apoptosis inducing compounds remained negative in the LLC-PK1 cells. In contrast, all test compounds were negative in NRK-52E cells, irrespective of the presence/ absence of FBS in the medium used.

TBT-Cl and TBT-O exposure of the LLC-PK1 cells resulted in ambiguous results with Hoechst staining (Figure 1(C)). Therefore, additional testing was performed using DNA laddering.

\subsection{DNA Laddering}

TBT-O and TBT-Cl induced clear DNA laddering at low concentrations and short-term exposures in LLC-PK1 cells (Table 2, Figure 2). Under the same conditions, NRK-52E cells showed no laddering with TBT-Cl and only a smear without distinct laddering with TBT-O (Table 2). During exposure of both cell types it could be observed that in a certain number of cells the contact to the surrounding cells and to the substrate was less tight and some cells started floating. During cell harvesting these types of cells are typically lost during washing. In order to test whether an important cell fraction might be lost this way, these cells were specifically collected and analyzed. And indeed, these non-adherent cells from both cell types showed distinct DNA laddering patterns at a minimum of $0.5 \mu \mathrm{M}$ TBT-Cl and after 2 hours of exposure (Table 2, Figures 2-3).

\section{Discussion}

This study aimed to investigate the suitability of the renal cell lines NRK-52E and LLC-PK1 for mid to late stage apoptosis research using chromatin condensation and DNA fragmentation as endpoints under standard cell culture conditions, i.e. in the presence of serum. Despite that many other investigators used serum-depleted cells, this was omitted here for two reasons: 1) the presented work should set the basis for future testing using compounds that require binding to serum components for membrane
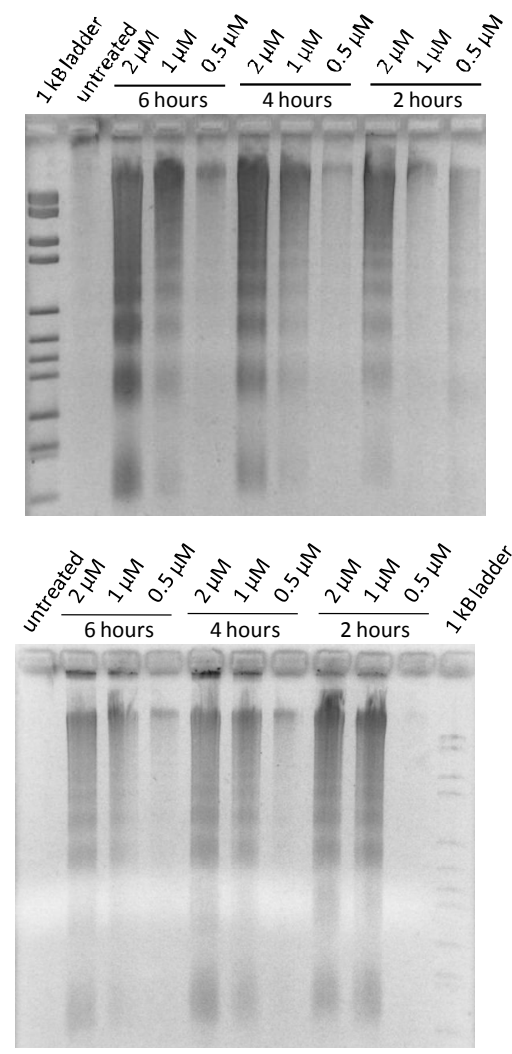

Figure 2. DNA laddering in non-adherent and adherent LLC-PK1E cells after exposure to TBT-CI. Left, floating cells; right, adherent cells.

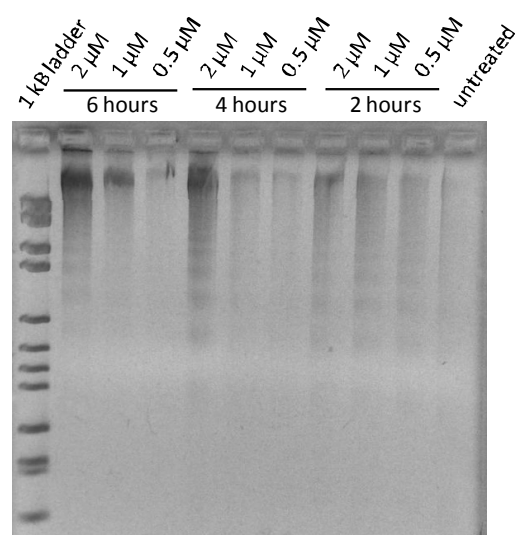

Figure 3. DNA laddering in non-adherent NRK-52E cells after exposure to TBT-CI. 
Table 2. DNA laddering results in LLC-PK1 and NRK-52E cells.

\begin{tabular}{|c|c|c|c|c|c|c|}
\hline \multirow{2}{*}{ Substance } & \multirow{2}{*}{$\begin{array}{c}\text { Final } \\
\text { concentrations }(\mu \mathrm{M})\end{array}$} & \multirow{2}{*}{$\begin{array}{l}\text { Exposure } \\
\text { time (h) }\end{array}$} & \multicolumn{2}{|c|}{ LLC-PK1 } & \multicolumn{2}{|c|}{ NRK-52E } \\
\hline & & & adherent & non-adherent & adherent & non-adherent \\
\hline TBT-O & $0.5-10$ & $3-6$ & $\geq 0.5 \mu \mathrm{M}(\geq 4 \mathrm{~h})(+)$ & n.d. & $\geq 3 \mathrm{~h}(?)$ & n.d. \\
\hline TBT-Cl & $0.5-2$ & $2-6$ & $\geq 1 \mu \mathrm{M}(\geq 2 \mathrm{~h})(+)$ & $\geq 0.5 \mu \mathrm{M}(\geq 2 \mathrm{~h})(+)$ & no effect & $\geq 0.5 \mu \mathrm{M}(\geq 2 \mathrm{~h})(+)$ \\
\hline
\end{tabular}

n.d., not determined; (+) distinct laddering patterns; (?) weak smear.

transport, i.e. similar to the in vivo situation; and 2) serum deprivation was demonstrated to trigger apoptosis in renal cells [16].

As apoptotic cell death is an extremely complex process, more than one endpoint is necessary to achieve reproducible results. Depending on cell type and apoptotic pathway, not all known features may be observable within one experiment. Also, differentiation between necrosis and apoptosis may be difficult. Correspondingly chromatin condensation and DNA fragmentation were chosen as endpoints in the study presented here, and only substances positively tested in the Hoechst staining experiments were subjected to further testing.

Seven known apoptosis inducers were used in the Hoechst staining assay, i.e. $\mathrm{CdCl}_{2}$, DTT, $\mathrm{NaCl}, \mathrm{HgCl}_{2}$, TBT-O, TBT-Cl and staurosporine, but only the last three elicited apoptosis in LLC-PK1 cells when tested under standard conditions (in the presence of serum). TBT-O and TBT-Cl had been previously shown to induce apoptosis using the same methods and at similar concentrations for example in rat thymocyte cultures and Jurkat cells, respectively [7-9]. Staurosporine induced apoptosis after exposure to $100 \mathrm{nM}$ for 4 hours. This is in good agreement with data from other investigators using human glioma cells (U251MG) or human kidney cells (HK-2) [12,13]. The four compounds that elicited no apoptotic response in the Hoechst assay in the presence of serum were retested under serum-deprived conditions whereby $\mathrm{CdCl} 2$ and $\mathrm{HgCl}_{2}$ elicited an apoptotic response, albeit only at high concentrations and long incubation times. $\mathrm{CdCl}_{2}$ and $\mathrm{HgCl}_{2}$ induced DNA laddering in LLCPK1 cells was observed previously under similar conditions [5,3], although very high $\mathrm{HgCl}_{2}$ concentrations $(\geqslant$ $100 \mu \mathrm{M})$ were reported to induce necrotic cell death [3].

Hypertonic $\mathrm{NaCl}$ was shown to induce caspase-3 mediated apoptosis at $\geq 550$ mosmol kg- $\mathrm{H}_{2} \mathrm{O}[2,6,14]$ in the mouse renal medullary mIMDCD3 cell line. In contrast to the latter, hypertonic $\mathrm{NaCl}$ had not apoptotic effect in LLC-PK1 in the presence or absence of serum, in the study presented here.

DTT was successfully used by van de Water et al. in rat renal proximal tubular cells (PTC) resulting in significant DNA fragmentation following exposure to 10 $\mathrm{mM}$ for 6 hours [11]. In other cell lines e.g. human leukemia HL-60 cells, late stage apoptosis (DNA fragmen- tation) was observed already after 3 - 4 hours exposure to 2 mM DTT [10].

Staurosporine induced the typical features of apoptosis in the Hoechst stain, i.e. half-moon-shaped chromatin condensation at the nuclear borders. In contrast, TBT-O and TBT-Cl resulted in ambiguous staining patterns (e.g. disrupted cells and nuclei), which were not readily distinguishable from necrosis. Consequently, TBT-O and TBT-Cl were further tested using the DNA-laddering assay that allowed confirmation of apoptosis.

Contrary to expectations, NRK-52E cells did not respond to known apoptosis inducing compounds, irespective of the concentrations and exposure durations used or the presence/absence of FBS in the media. Despite that this cell line has been frequently reported to be a useful model for understanding the mechanisms underlying apoptosis, albeit using other compounds [17-20], the results obtained in this study presented here shed some doubt as to the suitability of the model to study apoptosis.

When adherent and non-adherent NRK-52E cells were investigated separately using the DNA laddering assay, apoptosis could be detected with TBT-O and TBT-Cl in detached cells only. This suggested that the apoptotic cell fraction may be lost for Hoechst analysis at an early time point during compound incubation due to cell detachment. Although a similar observation was made for LLCPK1 cells, the degree and number of detached cells was not as pronounced as in NRK-52E.

The latter raises the question whether cells that enter apoptosis detach from the surface as a consequence of apoptosis or whether the cells detach from the surface first which then triggers apoptosis. Cells can become detached from their substrate as a result of damage to actin filaments and subsequently enter apoptosis through loss of cell-matrix contacts. This is a well-known feature of renal cells [11] and is also sometimes observed in vivo, for example in ochratoxin-exposed rats [21].

In literature, statements are controversial with respect to the potential of the investigated cell lines to undergo apoptosis, be this a consequence of different strains provided by the cell line collections (ATCC, ECACC, DSMZ etc.) or varying cell culture and exposure conditions of different investigators.

In summary, LLC-PK1 cells, but not NRK-52E cells, 
are suitable models of mid to late stage apoptosis under the tested conditions. Of the compounds tested, only TBT-O, TBT-Cl and staurosporine were shown to be suitable positive controls for future testing. It can also be concluded from this study that "positive controls" may in fact not work as positive controls in some cell lines and that a thorough establishment of true "positive controls" including their underlying cellular mechanisms is required prior to embarking on the investigation of in induction of apoptosis by some unknown compounds.

\section{Acknowledgements}

The authors like to thank K. Kobras for her assistance with assay performance.

\section{REFERENCES}

[1] A. Wyllie, "Glucocorticoid-Induced Thymocyte Apoptosis is Associated with Endogenous Endonuclease Activation," Nature, Vol. 284, No. 5756, 1980, pp. 555-556. doi:10.1038/284555a 0

[2] N. Dmitrieva, L. Michea, G. Rocha and M. Burg, "Cell Cycle Delay and Apoptosis in Response to Osmotic Stress," Comparative Biochemistry and Physiology Part A: Molecular \& Integrative Physiology, Vol. 130, No. 3, 2001, pp. 411-420. doi:10.1016/S1095-6433(01)00439-1

[3] K. Duncan-Achanzar, J. Jones, M. Burke, D. Carter and Hn. Laird, "Inorganic Mercury Chloride-Induced Apoptosis in the Cultured Porcine Renal Cell Line LLC-PK1," Journal of Pharmacology and Experimental Therapeutics, Vol. 277, 1996, pp. 1726-1732.

[4] P. Goering, D. Thomas, J. Rojko and A. Lucas, "Mercuric Chloride-Induced Apoptosis is Dependent on Protein Synthesis," Toxicology Letters, Vol. 105, No. 3, 1999, pp. 183-195. doi:10.1016/0378-4274(99)00002-8

[5] M. Matsuoka and K. Call, "Cadmium-Induced Expression of Immediate Early Genes in LLC-PK1 Cells," Kidney International, Vol. 48, No. 2, 1995, pp. 383-389. doi:10.1038/ki.1995.306

[6] L. Michea, D. Ferguson, E. Peters, P. Andrews, M. Kirby and M. Burg, "Cell Cycle Delay and Apoptosis are Induced by High Salt and Urea in Renal Medullary Cells," American Journal of Physiology Renal Physiology, Vol. 278, No. 2, 2000, pp. 209-218.

[7] M. Raffray, D. McCarthy, R. Snowden and G. Cohen, "Apoptosis as a Mechanism of Tributyltin Cytotoxicity to Thymocytes: Relationship of Apoptotic Markers to Biochemical and Cellular Effects," Toxicology and Applied Pharmacology, Vol. 119, No. 1, 1993, pp. 122-130. doi:10.1006/taap.1993.1051

[8] H. Stridh, E. Fava, B. Single, P. Nicotera, S. Orrenius and M. Leist, "Tributyltin-Induced Apoptosis Requires Glycolytic Adenosine Trisphosphate Production," Chemical Research in Toxicology, Vol. 12, No. 10, 1999, pp. 874882. doi:10.1021/tx990041c

[9] H. Stridh, S. Orrenius and M. Hampton, "Caspase Involvement in the Induction of Apoptosis by the Environ- mental Toxicants Tributyltin and Triphenyltin," Toxicology and Applied Pharmacology, Vol. 156, No. 2, 1999, pp. 141-146. doi:10.1006/taap.1999.8633

[10] L. Tartier, Y. McCarey, J. Biaglow, I. Kochevar and K. Held, "Apoptosis induced by Dithiothreitol in HL-60 Cells Shows Early Activation of Caspase 3 and is Independent of Mitochondria," Cell Death \& Differentiation, Vol. 7, No. 10, 2000, pp. 1002-1010. doi:10.1038/sj.cdd.4400726

[11] B. Van de Water, M. Kruidering and J. Nagelkerke, "FActin Disorganization in Apoptotic Cell Death of Cultured Rat Renal Proximal Tubular Cells," American Journal of Physiology Renal Physiology, Vol. 270, 1996, pp. F593-F603.

[12] Y. Wu, D. Connors, L. Barber, S. Jayachandra, U. Hanumegowda and S. Adams, "Multiplexed Assay Panel of Cytotoxicity in HK-2 Cells for Detection of Renal Proximal Tubule Injury Potential of Compounds," Toxicology In Vitro, Vol. 23, No. 6, 2009, pp. 1170-1178. doi:10.1016/j.tiv.2009.06.003

[13] F. Yamasaki, S. Hama, H. Yoshioka, Y. Kajiwara, K. Yahara, K. Sugiyama, Y. Heike, K. Arita and K. Kurisu, "Staurosporine-Induced Apoptosis is Independent of p16 and p21 and Achieved via Arrest at G2/M and at G1 in U251MG Human Glioma Cell Line," Cancer Chemotherapy and Pharmacology, Vol. 51, 2003, pp. 271- 283.

[14] Z. Zhang, W. Tian and D. Cohen, "Urea Protects from the Proapoptotic Effect of $\mathrm{NaCl}$ in Renal Medullary Cells," American Journal of Physiology Renal Physiology, Vol. 279, No. 2, 2000, pp. F345- F352.

[15] B. Zhivotovsky, A. Samali and S. Orrenius, "Determination of Apoptosis and Necrosis," In: M. Maines, Ed., Current Protocols in Toxicology, John Wiley \& Sons, New York, 2001, pp. 2.2.1-2.2.34.

[16] J. Li, S. Zelenin, A. Aperia and O. Aizman, "Low Doses of Ouabain Protect from Serum Deprivation-Triggered Apoptosis and Stimulate Kidney Cell Proliferation via Activation of NF-kappaB," Journal of the American Society of Nephrology, Vol. 17, No. 7, 2006, pp. 1848-1857. doi:10.1681/ASN.2005080894

[17] C. Guo, H. Yuan and Z. He, "Melamine Causes Apoptosis of Rat Kidney Epithelial Cell Line (NRK-52E Cells) via Excessive Intracellular ROS (Reactive Oxygen Species) and the Activation of p38 MAPK Pathway," Cell Biology International, Vol. 26, 2012, pp. 383-389. doi:10.1042/CBI20110504

[18] M. Davis, M. Smith, S. Chang and B. Trump, "Characterization of a Renal Epithelial Cell Model of Apoptosis Using Okadaic Acid and the NRK-52E Cell Line," Toxicologic Pathology, Vol. 22, No. 6, 1994, pp. 595-605. doi:10.1177/019262339402200604

[19] S. Lee, J. Choi and M. Cho, "Apoptosis, bcl2 Expression, and Cell Cycle Analyses in Nickel(II)-Treated Normal Rat Kidney Cells," Journal of Korean Medical Science, Vol. 16, No. 2, 2001, pp. 165-168.

[20] L. Wang, K. Matsushita, I. Araki and M. Takeda, "Inhibition of c-Jun N-Terminal Kinase Ameliorates Apoptosis Induced by Hydrogen Peroxide in the Kidney Tubule Epithelial Cells (NRK-52E)," Nephron, Vol. 91, 2002, pp. 
142-147. doi:10.1159/000057616

[21] T. Rásonyi, J. Schlatter and D. Dietrich, "The Role of Alpha2u-Globulin in Ochratoxin A Induced Renal Toxic- ity and Tumors in F344 Rats," Toxicology Letters, Vol. 104, No. 1-2, 1999, pp. 83-92.

doi:10.1016/S0378-4274(98)00347-6 